\title{
A Macro and Micro-Level Evaluation of Stakeholders' Collaboration for Sustainable City Logistics Operations
}

\author{
Taiwo Adetiloye \\ Concordia Institute for Information and Systems Engineering (CIISE), Montréal, Canada \\ E-mail:t_adeti@encs.concordia.ca (Corresponding Author) \\ Gul Pervez \\ Concordia Institute for Information and Systems Engineering (CIISE), Montréal, Canada \\ E-mail: g_pervez@encs.concordia.ca
}

\begin{abstract}
City logistics involves movement of city goods in urban areas respecting the municipal and administrative guidelines. The key goals of city logistics planning are maximizing vehicle movement and utilization, while minimising vehicle emissions and traffic congestion. Collaboration is vital to managing city logistics operations efficiently. Collaboration can take place in the form of goods consolidation, sharing of resources, information sharing, and so on. Two categories of models are proposed to evaluate these collaboration strategies. At the macro level, we present the collaboration matrix model; and at the micro level, we present the operational level model. The macro-level model focuses on the strategic decision making process necessary for stakeholders' collaboration given the socio-cultural characteristics, economic, and environmental constraint factors, while the micro-level model applies the collaboration decision-making criteria derived from the macro-level analytic result to improve the activities of the city logistics operators. Results of the computational testing of our methodology on vehicle selection, goods to vehicle assignment, goods distribution and environmental impact assessment are discussed, showing that the collaboration strategies of stakeholders, if optimized, can improve city logistics operations. The proposed work is novel and has strong practical applicability for logistics planners and decision makers in planning right collaboration strategies for sustainable city logistics operations.
\end{abstract}

Keywords: city logistics, collaboration planning, goods distribution, sustainability, stakeholder

\section{INTRODUCTION}

City logistics (CL), as defined by Taniguchi et al.(1999, 2001), is "the process for totally optimizing the logistics and transport activities by private companies in urban areas while considering the traffic environment, the traffic congestion and energy consumption within the framework of a market economy". The main purpose of CL is to reduce city traffic congestion caused by freight-vehicle movement, improving vehicle utilization; and reducing emissions and pollutions without penalizing the city social and economic activities (Crainic et al., 2011). Stathopoulos et al. (2012) stated that CL have a vital role to play in minimizing the negative impacts of freight movements, pollution and congestions, within urban areas. The freight transport (Lorries > 3.5 tons) constitutes about $10 \%$ of total traffic within urban areas (Crainic and Sgalambro, 2009b). A city with high traffic of freightvehicle movement, emissions and pollutions from moving freight-vehicles with the resultant effect on socio-economic activities of the city creates major obstacles for sustainable CL operations. Involved in CL operations are the key stakeholders, participants or actors comprising of shippers, residents also known as clients or customers, freight carriers, and administrator (Taniguchi et al., 2001) within an environment. The subsystems, connected through flows, are the different types of collaborative-commerce (c-commerce) that can be used by stakeholders in CL planning. The Gartner Group (1999) described c-commerce as the "dynamic collaboration among employees, business partners and customers throughout a trading community or market." Consequently, the robust technologies of today provide for adaptation of c-commerce transactions through collaborations for CL planning. Hence, our objective is to provide meaningful insights on effective collaboration of CL stakeholders using the basic and major approach of c-commerce applied for development of two CL models: the collaboration matrix model and the operational level model.

The rest of the paper is organised as follows. In Section 2 we formally present the contributions towards enhancing supply chain collaboration as related to CL systems. Section 3 describes our CL problem. The methodologies are discussed in Section 4. Section 5, introduce the numerical applications. Section 6 concludes the paper.

\section{LITERATURE REVIEW}

Collaboration is often discussed in the large domain of supply chain management (SCM) of which CL is a subset. Some aspects of SCM are aimed at ensuring effective collaboration strategies of the stakeholders (Taniguchi et al., 2001, Simatupang and Sridharam, 2002; Roy et al., 2006; Simonot and Roure, 2007; Lambert, 2008; Evrard Samuel and Spalanzani, 2009; Gonzalez-Feliu and Morana, 2011) for sustainable city logistics operations. With the global supply chain comes its numerous challenges and opportunities (Beamon, 2008); as such, by effective collaboration, CL scientists and practitioners are able to make better informed decisions on the vehicle routing 
and scheduling problems and assess the impacts of daily vehicle transportation activities on the city environment. The driving force of effective SCM is to encourage stakeholders' collaboration towards meeting the changing needs of customers that are situated at the end of the demand chain, to provide such strategic benefits as improved product design and more effective marketing (Horvath, 2001). Pervez (2013) proposed pre-qualification criteria for potential suppliers and/or retailers for possible win-win collaboration with good information sharing, adequate information technology capabilities and measurements systems as vital factors that must be considered for ensuring long term collaboration. Collaboration between partners can only happen when all partners can profit with no gain for those that deviates by changing their own strategy unilaterally (Osborne and Rubinstein, 1994). And, from the retrospect of supply chain collaboration in 57 Philippine manufacturing and servicing sectors; Gloria and Talavera (2014) identified trust as critical success factor for joint planning and decision making, and information sharing. The variables or factors that need to be improve when designing collaborative supply chain from the perspective of suppliers and customers in organization's internal and external supply chain has been investigated by Udin et al.(2008) using an hybrid approach of a Knowledge-Based Collaboration $\mathrm{SCM}(\mathrm{KBCSCM})$ system. They utilize Gauging Absence of Prerequisites (GAP) and Analytic Hierarchy Process (AHP) techniques embedded in a Knowledge Based System (KBS) to support the supplier-customer strategic, integration, development and partnering in a supply chain collaborative framework. Simatupang and Sridharam (2002) present a life cycle model for collaboration approach, which consists of (1) engagement process (2) inter-dependence management, (3) implementation of operations and (4) evaluation of collaboration (Gonzalez-Feliu et al., 2013). In CL planning, (3) and (4) can be said to address the issues of freight movements, congestion and pollution in urban areas since they underscore the collaboration approach of CL stakeholders and their operations.

The collaboration of CL stakeholders with regards to environmental impact assessment offers various performance indicators on reducing congestion and freight-vehicle emissions-causing-pollution in the city. Particularly, it can be stated that environmental pollution, emissions of $\mathrm{CO}_{\mathrm{x}}, \mathrm{NO}_{\mathrm{x}}$ etc. from freight transports, the impacts of which pose great concerns to decision makers at city administrative level (Gragnani et al., 2003; Taylor, n.d; and, Awasthi and Proth, 2006), are often the direct and indirect consequences of the activities of city-dwellers. Taniguchi et al. (2001) classified such impacts into economy, energy, environmental, financial, and social with models for assessing their effects on the city. There is, of course, the need to reduce congestion and environmental impacts caused by freight-vehicle movement without infringing on the social and economic activities of the city (Crainic et al., 2011). Marquez et al. (2003) present a policy oriented model for the impact assessment of urban goods movement in relation to energy consumption, congestion and environmental concerns (pollution, greenhouse gas and noise) to help in local decision making. An environmental impact assessment model of urban goods movement aimed at local decision makers with plans for sustainable city development was developed by Segalou et al. (2003). CL stakeholders through collaboration must seek improved vehicle routing and scheduling plans to address congestions and environmental pollutions within the city. Dantzig and Ramser (1959), propose the vehicle routing and scheduling (VRP) for transport cost optimization. Taniguchi et al. (2012) recommend models of vehicle routing and scheduling or vehicle routing and scheduling with time window (VRPTW) as basic tools to address the challenges of city logistics systems. A variance of the vehicle routing and scheduling respecting the constraints of delivery time windows and government regulations was introduced by Awasthi and Proth (2006). They present a system based approach for city logistics decision making with the layout of a city logistics simulator called CILOSIM. The key steps of the CILOSIM framework were goods to vehicle assignment, vehicle routing and scheduling, and environment impact assessment. We seek to close the gap in the current works through effective collaboration strategies among the city logistics participants.

\section{PROBLEM DESCRIPTION}

Collaboration strategies for CL planning can be defined as the mechanisms for successful collaboration based on c-commerce subsystems, such as Business to business (B2B), Customer to Business (C2B), Business to Customer (B2C), Customer to Customer-also known as Client to Client- (C2C), Government to Business (G2B), and Employee to Business (E2B) and so on, by the stakeholders living in a city within an environment. We assume a basic knowledge of these subsystems; and further discussion on them can be found in Nemat (2011) and Plant (2000). We limit our scope on collaboration strategies to the following four key ccommerce subsystems: B2B, B2C, C2C, and C2B. These four c-commerce subsystems are often the basic and major means of doing businesses that provide mutual benefits to its stakeholders comprising of shippers, freight carriers and residents as well as administrators involved in CL operations. Two models are proposed for evaluation of collaboration strategies at the macro and micro level of city logistics operations. They are: collaboration matrix model at the macro or strategic level and operational level model at the micro level of CL system. With the aid of these models, we will provide answers to the following:

1. What can be inferred from the collaboration strategies of the CL stakeholders?

2. How can the collaboration strategies benefit CL stakeholders at the operational level?

The significance of these questions can be traced to the earlier questions posed by Barratt (2004): Why do we need to collaborate? Where can we collaborate and 
with whom should we collaborate? Over what activities can we collaborate? It has been said that greater success can be achieved when two or more independent firms, regardless of their size, function, or relative position join their supply chain processes towards the goal of creating improved value to their end customers (Horvath, 2001 and Simatupang and Sridharan, 2002).

\section{METHODOLOGIES}

Our solution approach for evaluating the stakeholders' collaboration strategies comprises of two levels namely: macro and micro-level. The macro-level model focuses on the strategic decision making process necessary for stakeholders collaboration given the socio-cultural characteristics, economic, environmental constraint factors; while, the micro-level model applies the collaboration decision-making criteria derived from the macro-level analytic result to improve the activities of the city logistics operators. The models corresponding to the macro and micro levels are the (1) Collaboration matrix model and (2) Operational level model.

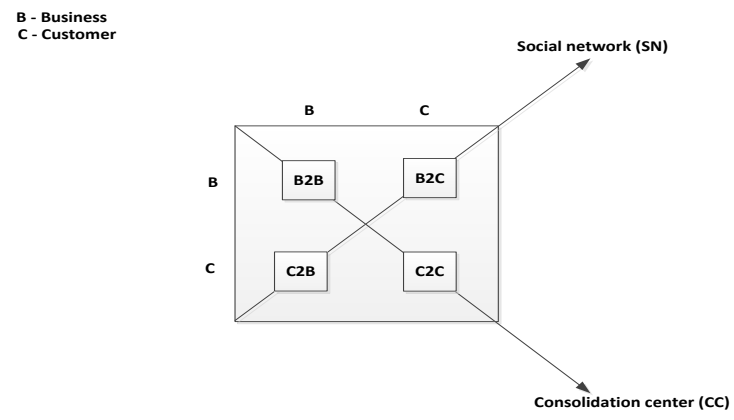

Figure 1. Collaboration matrix

\subsection{Collaboration Matrix Model}

The collaboration matrix (CM) model, also known as the collaboration square model, specifically represents the basic ecommerce subsystems, involving transactions between and amongst businesses and customers, as four squares enclosed in a larger square with two common diagonal arrows pointing outward and overlapping at the center. Figure 1, illustrates the $\mathrm{CM}$ model for the $\mathrm{B} 2 \mathrm{~B}, \mathrm{~B} 2 \mathrm{C}, \mathrm{C} 2 \mathrm{C}$, and $\mathrm{C} 2 \mathrm{~B}$ subsystem. The squares in the upper horizontal row that is, B2B and B2C- enjoy greater financial popularity when compared to the squares in the lower horizontal row - that is, $\mathrm{C} 2 \mathrm{~B}$ and $\mathrm{C} 2 \mathrm{C}$. Also, the squares on the left vertical column - that is, B2B and $\mathrm{C} 2 \mathrm{~B}-$ generate greater awareness and size when compared to the squares on the right vertical column B2C and C2C. Furthermore, the two diagonal lines with outward pointing arrows, which are consolidation center (CC) and social Network (SN), indicate that while $\mathrm{B} 2 \mathrm{~B}$ and $\mathrm{C} 2 \mathrm{C}$ subsystems could adopt $\mathrm{CC}$; on the other hand, $\mathrm{C} 2 \mathrm{~B}$ and $\mathrm{B} 2 \mathrm{C}$ could adopt $\mathrm{SN}$ as their respective collaboration strategies. It can be said that $\mathrm{CC}$ and $\mathrm{SN}$ are fast becoming a formidable collaboration strategies being used by collaborative communities towards sustainable CL operations.

At the macro-level, we will use the CM to evaluate collaboration subsystems on socio-cultural characteristics(S), economy (E) and environmental (En) impacts on the movement of goods inside the city. For the $\mathrm{CM}$ model, the objective function is given as:

$$
\begin{aligned}
& \operatorname{Maximize}\left(\sum_{i=1}^{n} B_{i} 2 B_{i}+\sum_{j=1}^{n} C_{j} 2 C_{j}\right)=C C \\
& \operatorname{Maximize}\left(\sum_{i=1}^{n} C_{i} 2 B_{i}+\sum_{j=1}^{n} B_{j} 2 C_{j}\right)=S N
\end{aligned}
$$

We make $\mathrm{n}=3$ for the three instances: $\mathrm{S}, \mathrm{E}$ and $\mathrm{En}$; and, we define the constraints as follow:

$$
\begin{aligned}
& \sum_{i=1}^{3} B_{i} 2 B_{i}=100 \% \\
& \sum_{j=1}^{3} C_{j} 2 C_{j}=100 \% \\
& \sum_{i=1}^{3} C_{i} 2 B_{i}=100 \% \\
& \sum_{j=1}^{3} B_{j} 2 C_{j}=100 \% \\
& B_{i} 2 B_{i} \geq 0, C_{i} 2 B_{i} \geq 0 \\
& C_{j} 2 B_{j} \geq 0, B_{j} 2 C_{j} \geq 0
\end{aligned}
$$

where $B_{1} 2 B_{1}, \quad B_{2} 2 B_{2}, B_{3} 2 B_{3} \quad \epsilon+\mathbb{R}$ are the percentage weight randomly assigned to each of the collaboration intent on socio-cultural characteristics (S), economy (E) and environment (En) impact. Similar representation can be made for Equations (3.2) to (3.4). In the line graph shown in Figure 2, collaboration: positive $(+)$; undecided: nil (0); and non-collaboration or competition: negative (-). Figure 3 and Table 1 describes how to derive the weighted collaboration intent for $\mathrm{SN}$ and $\mathrm{CC}$ based on the four subsystems and the conclusions that can be made. It can be assumed that the stakeholders' collaboration is engendered by their willingness to reach a consensus decision through cooperative games as they seek to find a feasible CM while considering various strategies (see Figure 4).

$$
\overleftrightarrow{\text { Non collaboration (-) }} \quad \text { Undecided (0) Collaboration }(+)
$$

Figure 2. Line graph for weighted collaboration intent 


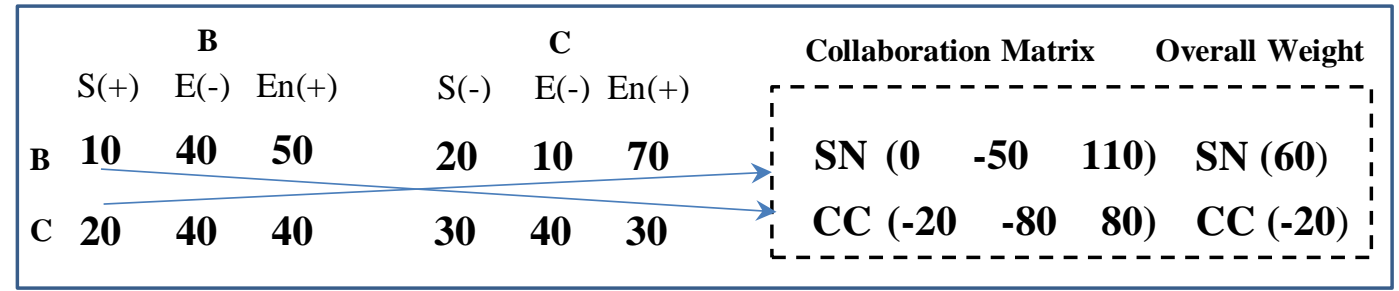

Figure 3. Collaboration matrix for $\mathrm{B} 2 \mathrm{~B}, \mathrm{~B} 2 \mathrm{C}, \mathrm{C} 2 \mathrm{~B}$ and $\mathrm{C} 2 \mathrm{C}$

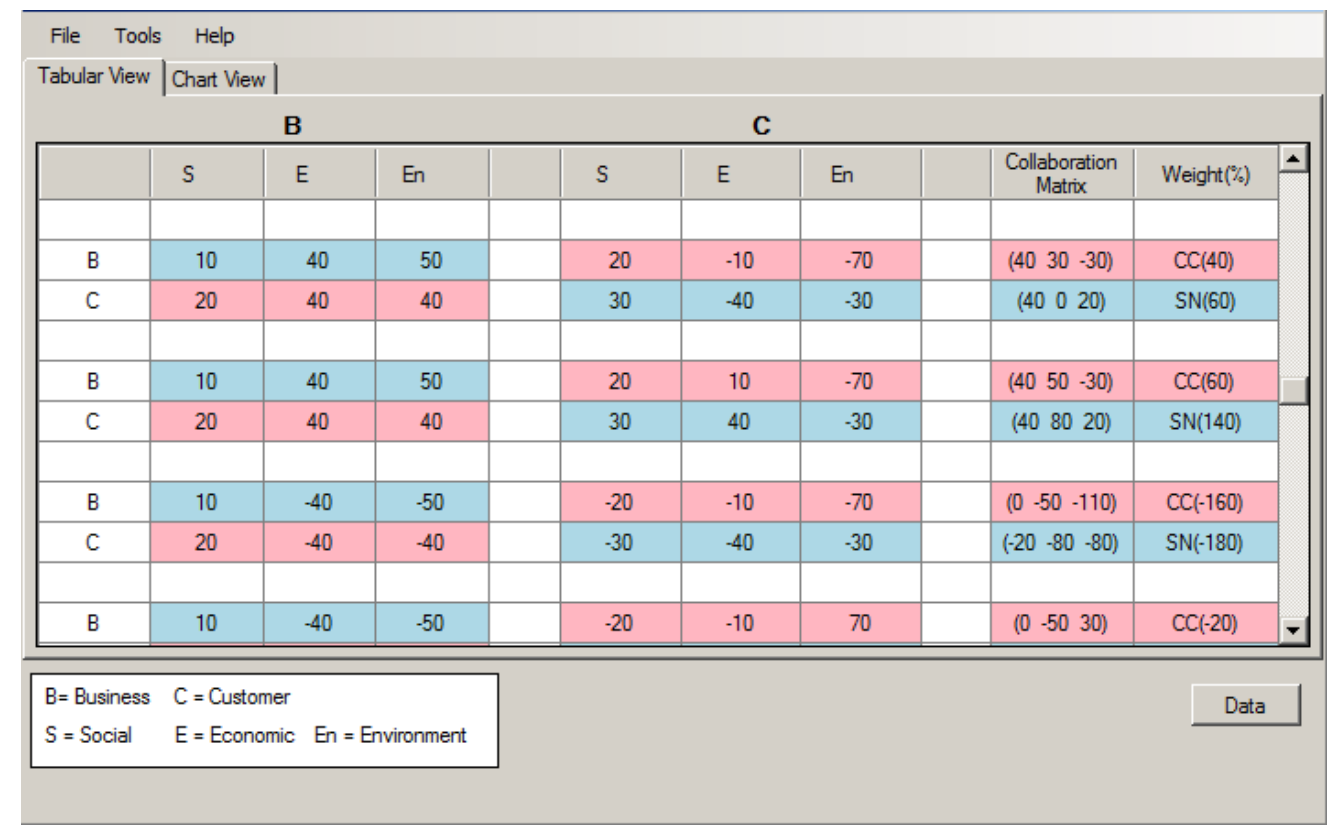

Figure 4. Example of stakeholder's collaboration strategies in wider scope

Table 1. Evaluation of test case

\begin{tabular}{|c|c|c|}
\hline Option & Description of CM & Conclusions \\
\hline \multirow[b]{2}{*}{1} & $\begin{array}{l}\text { C2B has weighted collaboration intent of } 20 \% \text { for S, non- } \\
\text { collaboration intent of } 40 \% \text { for } E \text { and } 40 \% \text { collaboration } \\
\text { intent for En, i.e. }(20,-40,40) \text {. }\end{array}$ & \multirow{2}{*}{ 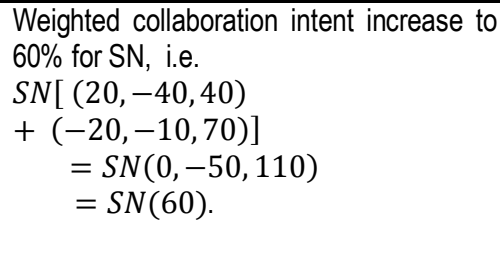 } \\
\hline & $\begin{array}{l}\text { B2C has weighted non-collaboration intent of } 20 \% \text { for } S \text {, } \\
\text { non-collaboration intent of } 10 \% \text { for } E \text { and } 70 \% \\
\text { collaboration intent for En, i.e. }(20,-10,70) \text {. }\end{array}$ & \\
\hline \multirow[b]{2}{*}{2} & $\begin{array}{l}\text { B2B has weighted collaboration intent of } 10 \% \text { for } S \text {, non- } \\
\text { collaboration intent of } 40 \% \text { for } E \text { and } 50 \% \text { collaboration } \\
\text { intent for } E n \text {, ,i.e. }(10,-40,50) \text {. }\end{array}$ & \multirow{2}{*}{$\begin{array}{l}\text { Weighted collaboration intent decrease to } \\
\begin{aligned} 20 \% \text { for } C C, \text { i.e. } \\
\begin{aligned} C C & (10,-40,50)+(-30,-40,30)] \\
& =C C(-20,-80,80) \\
& =C C(-20) .\end{aligned}\end{aligned}\end{array}$} \\
\hline & $\begin{array}{l}\mathrm{C} 2 \mathrm{C} \text { has weight non-collaboration intent of } 30 \% \text { for } \mathrm{S} \text {, } \\
\text { non-collaboration intent of } 40 \% \text { for } \mathrm{E} \text { and } 30 \% \\
\text { collaboration intent for En, i.e. }(-30,-40,30) \text {. }\end{array}$ & \\
\hline
\end{tabular}

\subsection{Operational Planning Model}

The results obtained from the macro level $\mathrm{CM}$ with respect to $\mathrm{CC}$ derived from the $\mathrm{B} 2 \mathrm{~B}$ and $\mathrm{C} 2 \mathrm{C}$ collaboration are applied at the micro-level. This can be accomplished with the following steps:

1. CM (input filter)

2. Goods to vehicle assignment

3. Goods distribution

4. Environment impact assessment
Step 1, is the CM which serves to filter inputs going to the subsequent steps $2-4$ by defining relevant constraints for vehicle usage in the city. In Step 2-4 we extend the steps for investigating CL decision making proposed by Awasthi and Proth (2006). We, then, formed the conjoined models 1-4 which is called the operational planning model. They are inter-related via input and output variables as depicted in Figure 5relying on Arena simulation and Visual C\# programming using 64-bit 8GB 3.4GHz Intel Core i7- 
2600 run on Windows Operating System. These steps are of relevance to $\mathrm{CL}$ operations in that they help to optimize the stakeholders' collaboration strategy through improved decision making, allowing identification of criteria for goods assignment to vehicles and goods distribution, while reducing airpollutions from vehicle emissions.

Detailed descriptions of these steps are as follows:

\section{Step 1: CM (Input Filtering Of Vehicle Data)}

We use the CM model to perform filtering of goods vehicles based on satisfying constraints for compliance with vehicle usage in the city as given by:

1. Constraint: City restriction on vehicle size $\leq$ admissible vehicle size $\times$ collaborative intent on social-cultural characteristics

2. Constraint: Gains restriction from distribution (for plausible taxation purpose) $\geq$ admissible net profit $x$ collaborative intent on economy

3. Constraint: Environment restriction on pollutants $\geq$ admissible pollutants level $\times$ collaborative intent on environment

\section{Step 2: Goods to Vehicle Assignment Model}

The goods to vehicle assignment model allocates goods to vehicles respecting the load capacity of the vehicles. The vehicles are assumed to be trucks of varying capacities with permissible emission factors.

\section{Step 3: Goods Distribution Model}

The goods distribution model performs the scheduling and routing of goods vehicles from the source of destination, which takes in to account the delivery time window in line with the classical travelling salesman problem.

\section{Step 4: Environmental Impact Assessment Model}

The environmental impact assessment model evaluates the impact of goods movement on the city environment. Considerations for the environmental impact assessment model are the vehicle movements, congestion, incidents and other variables that form the bases for evaluating the pollution and emissions (COx, NOx) level for goods vehicles in the city.

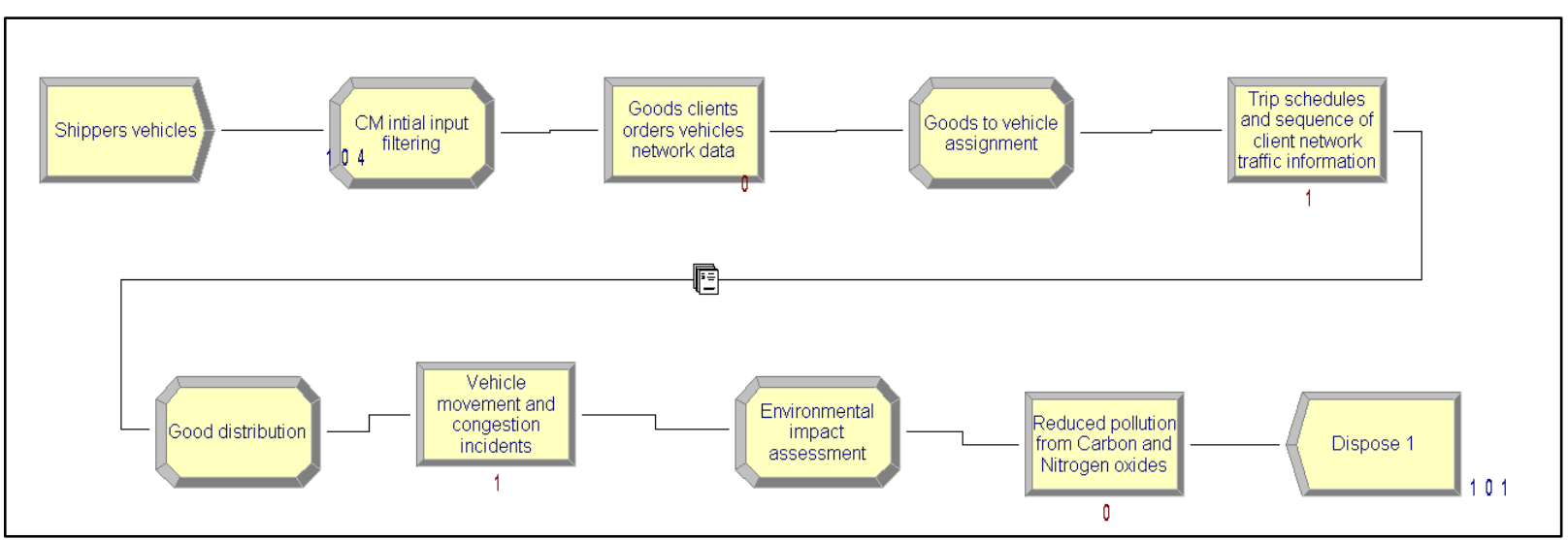

Figure 5. Operational planning model -adapted from Awasthi and Proth (2006)

\section{NUMERICAL APPLICATION}

For the purpose of our numerical application, we will consider the following theoretical cases which consist at the macro-level, five collaboration decision making test cases and, at the micro-level, six shippers each serving six clients or residents, with their operations assumed to be within a city environment. At the macro-level, we have the collaboration matrix model and at the micro-level, we have the operation planning model. The complementarity of our macrolevel and micro-level analysis used to address collaboration planning problems is to find a measure of the intents of decision makers to collaborate at the macro level; for example from business-to-customer and vice-versa, the outcome of which is the determination of their weighted collaborative intents that might influence the activities of city operators at the micro-level of city logistics. The macro-level analysis serves to evaluate the socio-cultural characteristics, economy and environmental impacts, and other factors deemed vital to the performance of city logistics systems within the framework of the basic and major subsystems, $\mathrm{B} 2 \mathrm{~B}, \mathrm{~B} 2 \mathrm{C}, \mathrm{C} 2 \mathrm{~B}$, and $\mathrm{C} 2 \mathrm{C}$, that are (rapidly) unifying into either consolidation centers or social networks; while, the micro-level model finds a basis for the application of the macro level model at the level of operations of the city logistics operators. Specifically, we focus on the use of the macro-level models for consolidation centers at the micro-level. The visibility of consolidation centers, unlike the invisibility of social network, makes it easier to place into theoretical and practical perspectives. We envisage that future work could find the usability of the macro-level models with regards to social networks at the microlevel of city logistics operations.

\subsection{Macro-Level Analysis}

We shall answer the question of "Which test case is best suited for collaboration from the B2B, B2C, C2B, and $\mathrm{C} 2 \mathrm{C}$ subsystems in the formation of $\mathrm{SN}$ and $\mathrm{CC}$ considering the collaboration matrix and weighted collaboration intent (\%) of the test cases?" How were the test cases generated? Figure 6, illustrates the SN and $\mathrm{CC}$ weighted collaborative intents for five test cases We say that test case 1 can be considered satisfactory 
for collaboration towards $\mathrm{SN}$ and $\mathrm{CC}$ since their respective weighted collaboration intent are above zero percent. For test case 2, we see that the weighted intent is negative for the SN. For test case 3, there is positive weighted collaboration intents for the $\mathrm{SN}$ and negative weighted collaboration intents for $\mathrm{CC}$. Test case 4 may be well suited for collaboration because of the weighted collaboration intent of $\mathrm{SN}$ and $\mathrm{CC}$ being the maximum value from the five test cases. In Test case 5, the $0 \%$ weighted collaborative intent for $\mathrm{CC}$ implies an indecision on whether or not to collaborate. In order to achieve the objective of collaboration within the CL framework for the consolidation centers, $\mathrm{CC}$, the test case 4 can be chosen for its optimum value for $\mathrm{CC}$.

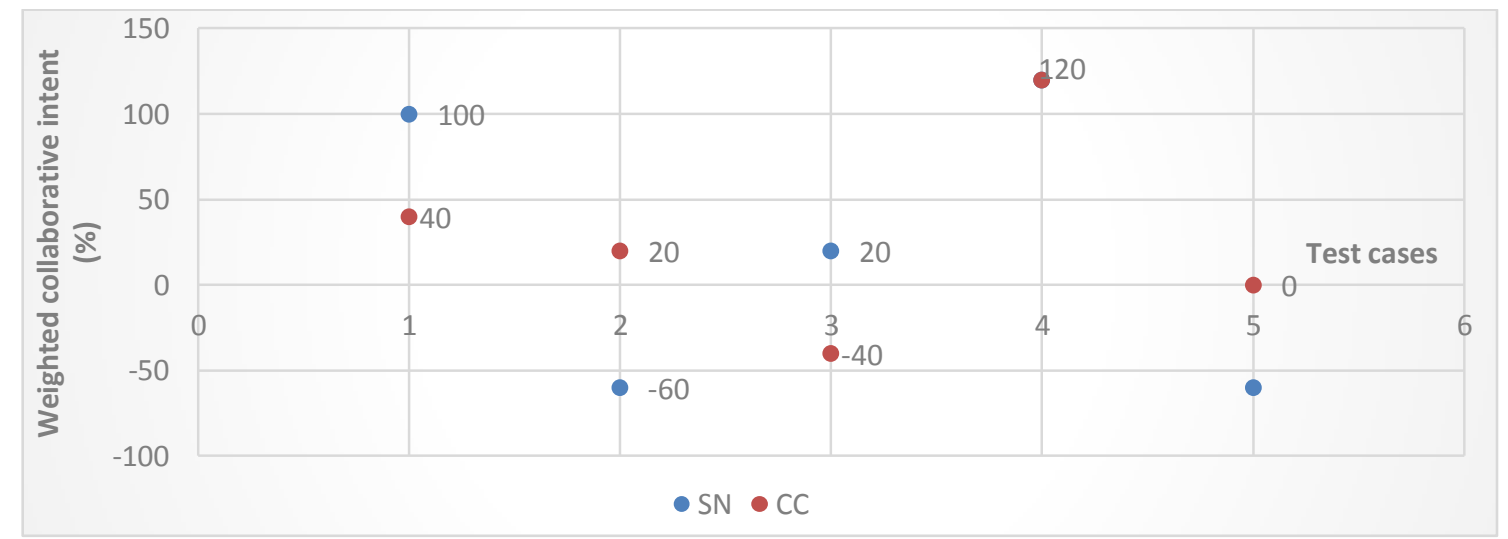

Figure 6. Example of $\mathrm{SN}$ and $\mathrm{CC}$ weighted collaborative intents

\subsection{Micro-Level Analysis}

We consider six shippers each serving four clients in a given city area. In Table $\mathbf{2}$, we can see the clients demand orders for the six shippers. The data on trucks available to each shipper is illustrated in Table 3. Our goal is to evaluate collaboration possibilities between them and decide which collaboration case helps to reduce vehicular emission respecting the vehicle routing and scheduling with time window (VRSTW). We used the operational planning model to assess collaboration possibilities between the various shippers.

\section{Step 1: CM Initial Input Filtering (Vehicle Selection Model)}

In this step, we carried out the filtering of the shippers' vehicles for compliance with restrictions on movement of shippers' vehicles in the city centers. To achieve this, we can select Test case 4 with a likely collaborative matrix $(40,0,80)$ assigned to it high weighted collaborative intent of $120 \%$ for CC; then, for administrative purpose, the constraints that can be set are:

- Constraint: City restriction on vehicle size $\leq$ 6 tons $\times 40 \%$.

- Constraint: Gains on distribution (for plausible taxation purpose) $\geq \$ 5000 \times 0 \%$.

- Constraint: Environment restriction on emission factor $\geq \mathrm{E} 1 \times 80 \%$ OR $\mathrm{E} 2 \times 80 \%$.

The constraints can represent the admissible optimum values taking into consideration the weighted collaboration intents of data gotten from city logistics operators. Based on the constraints, we see that constraint $\mathrm{C} 1$ is fully satisfied by shippers $\mathrm{S} 1, \mathrm{~S} 6$ and $\mathrm{S} 4$ since the vehicles size for S1,S6 with trucks T1=2 ( $<2.4$ tons), and T2 =2.40=tons; and for S4, T7=1.5tons and $\mathrm{T} 8=1.5$ tons (both less than 2.4tons); the constraint is partially satisfied by S2 and S3 since the vehicle size for $\mathrm{S} 2$ trucks $\mathrm{T} 3=3.3$ ( $>2.4$ tons) and $\mathrm{T} 4=2$ (<2.4tons) while, for S3, vehicle size for it trucks T5=2 ( $<2.4$ tons) and $\mathrm{T} 6=3$ ( $>2.4$ tons); but, S5 failed to satisfy the constraints on vehicle size since $\mathrm{T} 9=4(>2.4$ tons) and $\mathrm{T} 10=3$ ( $>2.40$ tons). The constraints $\mathrm{C} 2$ and $\mathrm{C} 3$ are only met by shippers S1, S2, S3, S4 and S5 since they can satisfy the restrictions set by these constraints. While S1, S4 and S6 satisfy the three constraints. A necessary condition for the goods-to-vehicle assignments model is that the trucks must satisfy all the three constraints $\mathrm{C} 1, \mathrm{C} 2$ and $\mathrm{C} 3$. Table 4 summarizes the outcome of this filtering. It can be seen that the shippers S1, S2, S3, S4 and S6 fully satisfied the requirements for usage of their vehicles inside the city centers; we assume they all make profits.

\section{Step 2: Assignment of Goods to Vehicle (Goods to Vehicle Assignment Model)}

In this step, we assign the goods to the vehicles of shippers that had fully satisfied the rules set by the constraints on use of goods vehicles in the city. In order to fulfill the demands of clients itemized in Table 4, the possible assignments of goods to vehicles for the shippers S1, S2, S3 and S4 are provided in Table 5 with the plausible Cases 1.1 to 4.6. For example, for S1 (same as with S6) with two vehicles: truck T1 and truck $\mathrm{T} 2$, in Case 1.1 we assign $200 \mathrm{~kg}(=10 \times 20 \mathrm{~kg})$ to $\mathrm{T} 2$ for client $\mathrm{C} 1,20 \mathrm{~kg}(10 \times 2 \mathrm{~kg})$ to $\mathrm{T} 1$ for client $\mathrm{C} 2,100 \mathrm{~kg}$ $(=10 \times 10 \mathrm{~kg})$ to $\mathrm{T} 1$ for client $\mathrm{C} 3$, and then $80 \mathrm{~kg}(=20 \mathrm{~kg}$ $+60 \mathrm{~kg}$ ) to $\mathrm{T} 1$ for client $\mathrm{C} 4$. We can see that for this Case 1.1, that with this combination, three trips are made, two by T1 and one by T2. Similar explanations can be made for the loading of trucks for the other test cases by the shippers in which different possible combinations for loading of trucks can be derived. However, since the goal of this step is to ensure that maximum capacity utilization of vehicles takes place, we can say that for shippers S1 and S6, Case 1.7 and 
Case 1.8 have the minimum total number of vehicle trips (TNVT) taking into consideration the order upon which the goods have been assigned to trucks based on their load capacity as shown in Table $\mathbf{5}$.

Table 2. Clients demand orders for shippers S1, S2, S3, S4, S5 and S6

\begin{tabular}{|c|c|c|c|c|c|}
\hline Shippers & Clients & $\begin{array}{c}\text { No of packets to be } \\
\text { delivered(N) }\end{array}$ & $\begin{array}{c}\text { Size of } \\
\text { the packet(s) (units) }\end{array}$ & Time windows & $\begin{array}{c}\text { Quantity to be } \\
\text { delivered= }\left(N^{*} S\right)\end{array}$ \\
\hline \multirow{4}{*}{ s1 } & C1 & 10 & 20 & 9am-10am & 200 \\
\hline & $\mathrm{C} 2$ & 10 & 2 & 10am-11am & 20 \\
\hline & C3 & 10 & 10 & 11am-12pm & 100 \\
\hline & C4 & 10 & 6 & $12 p m-1 p m$ & 60 \\
\hline \multirow{4}{*}{ S2 } & C5 & 10 & 10 & 9am-10am & 100 \\
\hline & C6 & 10 & 5 & 9am-10am & 50 \\
\hline & $\mathrm{C7}$ & 20 & 10 & 9am-10am & 200 \\
\hline & $\mathrm{C} 8$ & 5 & 10 & $9 a m-12 p m$ & 50 \\
\hline \multirow{4}{*}{ S3 } & $\mathrm{C6}$ & 10 & 10 & 9am-10am & 100 \\
\hline & $\mathrm{C} 7$ & 10 & 5 & 9am-10am & 50 \\
\hline & $\mathrm{C} 8$ & 25 & 2 & $9 a m-12 p m$ & 50 \\
\hline & $\mathrm{C} 10$ & 10 & 10 & 9am-10am & 100 \\
\hline \multirow{4}{*}{ S4 } & $\mathrm{C7}$ & 10 & 5 & 9am-10am & 50 \\
\hline & $\mathrm{C} 8$ & 10 & 10 & $9 a m-12 p m$ & 100 \\
\hline & $\mathrm{Cg}$ & 1 & 30 & 9am-10am & 30 \\
\hline & $\mathrm{C} 11$ & 1 & 30 & $9 a m-10 a m$ & 30 \\
\hline \multirow{4}{*}{ S5 } & $\mathrm{C} 12$ & 10 & 5 & 9am-10am & 50 \\
\hline & $\mathrm{C} 13$ & 20 & 4 & 9am-11am & 80 \\
\hline & C14 & 5 & 10 & 9am-11am & 50 \\
\hline & $\mathrm{C} 15$ & 10 & 20 & 9am-11am & 200 \\
\hline \multirow{4}{*}{ S6 } & $\mathrm{C1}$ & 20 & 10 & 9am-10am & 200 \\
\hline & $\mathrm{C} 2$ & 10 & 2 & 10am-11am & 20 \\
\hline & C3 & 10 & 10 & $11 \mathrm{am}-12 \mathrm{pm}$ & 100 \\
\hline & C4 & 10 & 6 & $12 \mathrm{pm}-1 \mathrm{pm}$ & 60 \\
\hline
\end{tabular}

Table 3. Trucks available with shippers (S1- S6)

\begin{tabular}{|c|c|c|c|}
\hline Trucks with S1 & Load capacity (kg) & Vehicle size(tons) & Emission Factor \\
\hline $\begin{array}{l}\text { T1 } \\
\text { T2 }\end{array}$ & $\begin{array}{l}100 \\
200\end{array}$ & $\begin{array}{c}2 \\
2.4 \\
\end{array}$ & $\begin{array}{l}\text { E1 } \\
\text { E2 }\end{array}$ \\
\hline Trucks with S2 & Load capacity (kg) & Vehicle size(tons) & Emission Factor \\
\hline $\begin{array}{l}\text { T3 } \\
\text { T4 }\end{array}$ & $\begin{array}{l}100 \\
200 \\
\end{array}$ & $\begin{array}{c}3.30 \\
2 \\
\end{array}$ & $\begin{array}{l}\text { E2 } \\
\text { E1 }\end{array}$ \\
\hline Trucks with S3 & Load capacity (kg) & Vehicle size(tons) & Emission Factor \\
\hline $\begin{array}{l}\text { T5 } \\
\text { T6 } \\
\end{array}$ & $\begin{array}{l}100 \\
200 \\
\end{array}$ & $\begin{array}{l}2 \\
3 \\
\end{array}$ & $\begin{array}{l}\text { E1 } \\
\text { E2 }\end{array}$ \\
\hline Trucks with S4 & Load capacity $(\mathrm{kg})$ & Vehicle size(tons) & Emission Factor \\
\hline $\begin{array}{l}\mathrm{T} 7 \\
\mathrm{~T} 8 \\
\end{array}$ & $\begin{array}{l}50 \\
100\end{array}$ & $\begin{array}{l}1.5 \\
1.5 \\
\end{array}$ & $\begin{array}{l}\text { E1 } \\
\text { E2 }\end{array}$ \\
\hline Trucks with S5 & Load capacity (kg) & Vehicle size(tons) & Emission Factor \\
\hline $\begin{array}{c}\text { T9 } \\
\text { T10 }\end{array}$ & $\begin{array}{c}80 \\
200\end{array}$ & $\begin{array}{l}4 \\
3 \\
\end{array}$ & $\begin{array}{l}1.1 \mathrm{E} 1 \\
2 \mathrm{E} 2\end{array}$ \\
\hline Trucks with S6 & Load capacity (kg) & Vehicle size(tons) & Emission Factor \\
\hline $\begin{array}{l}\mathrm{T} 1 \\
\mathrm{~T} 2 \\
\end{array}$ & $\begin{array}{l}100 \\
200 \\
\end{array}$ & $\begin{array}{c}2 \\
2.4\end{array}$ & $\begin{array}{l}\text { E1 } \\
\text { E2 }\end{array}$ \\
\hline
\end{tabular}


Table 4. Shippers' vehicles selection

\begin{tabular}{|c|c|c|c|c|c|c|}
\hline \multirow[t]{2}{*}{ Shippers } & \multirow[t]{2}{*}{ Vehicles/Trucks } & \multicolumn{3}{|c|}{ Constraints } & \multirow[t]{2}{*}{ Accept/Reject trucks } & \multirow[t]{2}{*}{ Constraints inference } \\
\hline & & $\mathrm{C} 1$ & $\mathrm{C} 2$ & $\mathrm{C} 3$ & & \\
\hline \multirow[t]{2}{*}{ S1 } & T1 & $\sqrt{ }$ & $\sqrt{ }$ & $\sqrt{ }$ & Accept & Fully satisfied \\
\hline & $\mathrm{T} 2$ & $\sqrt{ }$ & $\sqrt{ }$ & $\sqrt{ }$ & Accept & Fully satisfied \\
\hline \multirow[t]{2}{*}{ S2 } & T3 & $x$ & $\sqrt{ }$ & $\sqrt{ }$ & Reject & Partially satisfied \\
\hline & T4 & $\sqrt{ }$ & $\sqrt{ }$ & $\sqrt{ }$ & Accept & Fully satisfied \\
\hline \multirow[t]{2}{*}{ S3 } & T5 & $\sqrt{ }$ & $\sqrt{ }$ & $\sqrt{ }$ & Accept & Fully satisfied \\
\hline & T6 & $x$ & $\sqrt{ }$ & $\sqrt{ }$ & Reject & Partially satisfied \\
\hline \multirow[t]{2}{*}{ S4 } & $\mathrm{T} 7$ & $\sqrt{ }$ & $\sqrt{ }$ & $\sqrt{ }$ & Accept & Fully satisfied \\
\hline & T8 & $\sqrt{ }$ & $\sqrt{ }$ & $\sqrt{ }$ & Accept & Fully satisfied \\
\hline \multirow[t]{2}{*}{ S5 } & T9 & $x$ & $\sqrt{ }$ & $\sqrt{ }$ & Reject & Partially satisfied \\
\hline & T10 & $x$ & $\sqrt{ }$ & $\sqrt{ }$ & Reject & Partially satisfied \\
\hline \multirow[t]{2}{*}{ S6 } & $\mathrm{T} 1$ & $\sqrt{ }$ & $\sqrt{ }$ & $\sqrt{ }$ & Accept & Fully satisfied \\
\hline & $\mathrm{T} 2$ & $\sqrt{ }$ & $\sqrt{ }$ & $\sqrt{ }$ & Accept & Fully satisfied \\
\hline$\sqrt{ }:$ Satisfied & $x:$ Not satisfied & & & & & \\
\hline
\end{tabular}

Table 5. Possible allocations of packets to trucks

\begin{tabular}{|c|c|c|c|c|c|}
\hline Load case number & \multicolumn{4}{|c|}{ Trucks with their loads } & TNVT \\
\hline \multicolumn{6}{|c|}{ Possible allocations of packets to trucks by $\mathrm{S} 1$ and $\mathrm{S} 6$} \\
\hline Case 1.1 & $\mathrm{~T} 1(100)$ & & & $\mathrm{T} 1(20+60)$ & 3 \\
\hline Case 1.2 & $\mathrm{~T} 1(20+60)$ & & & $\mathrm{T} 1(100)$ & 3 \\
\hline Case 1.3 & $\mathrm{~T} 1(100)$ & & & $\mathrm{T} 2(200)$ & 3 \\
\hline Case 1.4 & $\mathrm{~T} 2(100+20+60)$ & & & $\mathrm{T} 1(100)$ & 3 \\
\hline Case 1.5 & $\mathrm{~T} 1(100)$ & & & $\mathrm{T} 1(100)$ & 3 \\
\hline Case 1.6 & $\mathrm{~T} 1(100)$ & & & $\mathrm{T} 2(100+20+60)$ & 3 \\
\hline Case 1.7 & $\mathrm{~T} 2(200)$ & & $\mathrm{T} 2(100+60+$ & & 2 \\
\hline Case 1.8 & $\mathrm{~T} 2(100+60+20)$ & & $\mathrm{T} 2(200)$ & & 2 \\
\hline Case 1.9 & $\mathrm{~T} 1(20+60)$ & $\mathrm{T} 1(100)$ & $\mathrm{T} 1(100)$ & $\mathrm{T} 1(100)$ & 4 \\
\hline Case 1.10 & $\mathrm{~T} 1(100)$ & $\mathrm{T} 1(20+6 \mathrm{C}$ & $\mathrm{T} 1(100)$ & $\mathrm{T} 1(100)$ & 4 \\
\hline Case 1.11 & $\mathrm{~T} 1(100)$ & $\mathrm{T} 1(100)$ & $\mathrm{T} 1(20+60)$ & $\mathrm{T} 1(100)$ & 4 \\
\hline Case 1.12 & $\mathrm{~T} 1(100)$ & $\mathrm{T} 1(100)$ & $\mathrm{T} 1(100)$ & $\mathrm{T} 1(20+60)$ & 4 \\
\hline \multicolumn{6}{|c|}{ Possible allocations of packets to truck T4 by S2 } \\
\hline Case 2.1 & $\mathrm{~T} 4(200)$ & & $\mathrm{T} 4(100+50$ & & 2 \\
\hline Case 2.2 & $\mathrm{~T} 4(100+50+50)$ & & $\mathrm{T} 4(200)$ & & 2 \\
\hline \multicolumn{6}{|c|}{ Possible allocations of packets to truck T5 by S3 } \\
\hline Case 3.1 & $\mathrm{~T} 5(50+50)$ & & & $T 5(100)$ & 3 \\
\hline Case 3.2 & $\mathrm{~T} 5(100)$ & & & $\mathrm{T} 5(100)$ & 3 \\
\hline Case 3.3 & $\mathrm{~T} 5(100)$ & & & $\mathrm{T} 5(50+50)$ & 3 \\
\hline Case 3.4 & $\mathrm{~T} 5(100)$ & $\mathrm{T} 5(100)$ & $\mathrm{T} 5(50)$ & $\mathrm{T} 5(50)$ & 4 \\
\hline Case 3.5 & $\mathrm{~T} 5(50)$ & $\mathrm{T} 5(50)$ & $\mathrm{T} 5(100)$ & $T 5(100)$ & 4 \\
\hline \multicolumn{6}{|c|}{ Possible allocations of packets to truck T7 and T8 by S4 } \\
\hline Case 4.1 & $T 7(50)$ & $\mathrm{T} 8(100)$ & $\mathrm{T} 7(30)$ & $\mathrm{T} 7(30)$ & 4 \\
\hline Case 4.2 & $\mathrm{~T} 8(100)$ & $\mathrm{T} 7(30)$ & $\mathrm{T} 7(50)$ & $\mathrm{T} 7(30)$ & 4 \\
\hline Case 4.3 & $\mathrm{~T} 7(30)$ & $\mathrm{T} 7(30)$ & $\mathrm{T} 8(100)$ & $\mathrm{T} 7(50)$ & 4 \\
\hline Case 4.4 & $\mathrm{~T} 7(30)$ & T8(100) & $\mathrm{T} 7(30)$ & $\mathrm{T} 7(50)$ & 4 \\
\hline Case 4.5 & T8(100) & & $T 8(50+30$ & & 2 \\
\hline Case 4.6 & $T 8(50+30+30)$ & & T8(100) & & 2 \\
\hline
\end{tabular}


(Case 1.7, Case 1.8) > (Case 1.1, Case 1.2, Case 1.3, Case 1.4, Case 1.5, and Case 1.6) > (Case 1.9, Case 1.10, Case 1.11)

Also, for shippers S2 with two trucks T3 and T4, we can recall from the filtering carried out in the previous step, that truck T3 was rejected due to failure to meet the constraint on vehicle size restriction. Hence S2 can only use truck T4 (maximum capacity $=200 \mathrm{~kg}$ ) to supply its clients. The maximum capacity for vehicle utilization can best be achieved with two trips by allotting $200 \mathrm{~kg}$ $(20 \times 10)$ to $\mathrm{T} 4$ for first trip and $200 \mathrm{~kg}(100+50$ $+500)$ for the second trip or vise-versa, that is $200 \mathrm{~kg}$ $(100+50+500)$ for first trip and $200 \mathrm{~kg}(20 \times 10)$ for second trip by $\mathrm{T} 4$.

(Case $2.1=$ Case 2.2)

Likewise, shipper S3 has a single truck T5 as we can observe in the possible allocations of packets to truck T5.
(Case 3.1, Case 3.2, Case 3.3) > (Case 3.4, Case 3.5)

Therefore, for maximum capacity utilization of the truck, we can say that three trips can be made by T5. The disadvantage of a shipper using a single truck to meet the demands of its clients would be inefficiency due to time delay should the single truck develop a major fault that results in breakdown.

Finally, for shipper S4 with two trucks T7 (maximum capacity $=50$ ) and $\mathrm{T} 8$ (maximum capacity $=100$ ), we observe that with Case 4.5 and Case 4.6 two trips can be made taking into account the maximum capacity utilization of the vehicle within the time window as it can be observe that:

(Case 4.5, Case 4.6) > (Case 4.1, Case 4.2, Case 4.3, Case 4.4)

The data of the load case numbers having minimum trip lengths respecting minimum capacity utilization of vehicles as determined by the possible allocation of packets to trucks served are used in Step 3 for the routing and scheduling of vehicles.

Table 6. Schedules and possible routes

\begin{tabular}{|c|c|c|c|c|c|c|c|}
\hline $\begin{array}{c}\text { Collaboration } \\
\text { type }\end{array}$ & $\begin{array}{c}\text { Possible } \\
\text { combinations } \\
\text { between } \\
\text { shippers }\end{array}$ & Travel time & Clients & $\begin{array}{r}\text { Route } \\
\text { (with shortest path) }\end{array}$ & TNVT & $\begin{array}{r}\text { Total } \\
\text { trip } \\
\text { length }\end{array}$ & $\begin{array}{r}\text { Kinds of } \\
\text { vehicles } \\
\text { used(counts) }\end{array}$ \\
\hline \multirow{2}{*}{ FC } & \multirow{2}{*}{ S1-S6 } & \multirow{2}{*}{$\leq 9-1 \mathrm{pm}$} & $\mathrm{C} 2$ & (S1-S6)-C2(15) & \multirow{2}{*}{2} & \multirow{2}{*}{30} & \multirow{2}{*}{$\mathrm{T} 1, \mathrm{~T} 2$} \\
\hline & & & C1-C3-C4 & (S1-S6)-C1-C3-C4(15) & & & \\
\hline \multirow{4}{*}{ PC } & \multirow{2}{*}{ S2-S3 } & \multirow{2}{*}{$\leq 9-10 \mathrm{am}$} & C5 & (S2-S3)-C6(10) & \multirow{2}{*}{2} & \multirow{2}{*}{25} & \multirow{2}{*}{$\mathrm{T} 4, \mathrm{~T} 5$} \\
\hline & & & $\mathrm{C} 6, \mathrm{C} 7, \mathrm{C} 8$ & (S2-S3)-C5-C7-C8(15) & & & \\
\hline & S2-S4 & $\leq 9-10 \mathrm{am}$ & $\mathrm{C} 7, \mathrm{C} 8$ & (S2-S4)-C7-C8(15) & 1 & 15 & T4 or T7or T8 \\
\hline & S2-S3-S4 & $\leq 9-10 \mathrm{am}$ & $\mathrm{C} 7, \mathrm{C} 8$ & (S2-S3-S4)-C7-C8(10) & 1 & 10 & $\begin{array}{r}\text { T4 or T5 or } \\
\text { T7or T8 }\end{array}$ \\
\hline \multirow{8}{*}{ NC } & \multirow{3}{*}{ S2 } & $\leq 9 \mathrm{am}-12 \mathrm{pm}$ & $\begin{array}{r}\mathrm{C} 2 \\
\mathrm{C} 1, \mathrm{C} 3, \mathrm{C} 4\end{array}$ & $\begin{array}{r}\text { S1-C2(15) } \\
\text { S1-C1-C3-C4(15) }\end{array}$ & 2 & 30 & $\mathrm{~T} 1, \mathrm{~T} 2$ \\
\hline & & $\leq 9 \mathrm{am}-$ & $\mathrm{C} 6, \mathrm{C} 8$ & S2-C6-C7(20) & \multirow{2}{*}{1} & \multirow{2}{*}{35} & \multirow{2}{*}{ T4 } \\
\hline & & 11am & $\begin{array}{r}\mathrm{C}, \mathrm{C7} \\
\mathrm{C} 6\end{array}$ & $\begin{array}{r}\text { S2-C5-C8(15) } \\
\text { S3-C6(10) }\end{array}$ & & & \\
\hline & \multirow[t]{2}{*}{ S3 } & \multirow[t]{2}{*}{$\leq 9 a m-10 a m$} & C7-C8 & S3-C7-C8(10) & \multirow[t]{2}{*}{1} & \multirow[t]{2}{*}{45} & \multirow[t]{2}{*}{ T5 } \\
\hline & & & $\mathrm{C} 10$ & S3-C10(25) & & & \\
\hline & \multirow{2}{*}{ S4 } & \multirow{2}{*}{$\leq 9 \mathrm{am}-10 \mathrm{am}$} & $\mathrm{C} 7, \mathrm{C} 8$ & S4-C7-C8(15) & \multirow{2}{*}{2} & \multirow{2}{*}{40} & \multirow{2}{*}{$\mathrm{T7}, \mathrm{T} 8$} \\
\hline & & & C9, C11 & S4-C9-C11(25) & & & \\
\hline & S6 & $\leq 9 \mathrm{am}-12 \mathrm{pm}$ & $\begin{array}{r}\mathrm{C} 1 \\
\mathrm{C} 3, \mathrm{C} 4, \mathrm{C} 2\end{array}$ & $\begin{array}{r}\text { S6-C1(10) } \\
\text { S6-C3-C4-C2(20) }\end{array}$ & 2 & 30 & $\mathrm{~T} 1, \mathrm{~T} 2$ \\
\hline
\end{tabular}

\section{Step 3: Goods Distribution Model}

In this step, we perform the routing and scheduling of goods vehicles (or loaded trucks) with the minimum number of vehicle trips respecting delivery time windows in the principle of TSP using the Dijkstra's shortest path algorithm. In Table 5, for shippers S1 and $\mathrm{S} 2$, each with two similar trucks (T1 and T4) we select Case 1.7 and Case 1.8 with minimum number of vehicle trips of two; for shipper S2 with truck T4 we select Case 2.1 and Case 2.2 with minimum number of vehicle trips of two; and, for shipper S3 with truck T5 we select Case 3.1, Case 3.2 and Case 3.3 with minimum number of vehicle trips of three; while, for shipper S4 with trucks T1 and T4 we select Case 4.5 and 4.6 with minimum number of vehicle trips of two. The different schedules and possible routes for the goods vehicles for the cases is described in Table 6. The table describe the three collaboration types: no collaboration (NC), partial collaboration (PC) and full collaboration (FC) that can exist between shippers. Given the assumption that the routes followed by the vehicles conform to the principle of the TSP with goods delivered to clients in minimum time respecting delivery time windows; we can say that $\mathrm{PC}$ and FC of shippers satisfy these conditions, since the total trip length for PC and FC are lesser than that of 
NC between shippers. In numerical terms, it can be stated that:

Total trip lengths of FC + Total trip lengths of PC < Total trip lengths of $\mathrm{NC}$.

Step 4: Environmental impact assessment

In this step, we evaluate the impact of goods movement on the city environment in terms of pollution and emissions $\left(\mathrm{CO}_{2}, \mathrm{NO}_{\mathrm{x}}\right.$ etc. $)$. The goal is to minimize the number of vehicle trips or the total trip length to favor minimum vehicular emissions. The results are presented in Table 7. In numerical terms, we can say that vehicular emission of FC + vehicular emission of $\mathrm{PC}<$ vehicular emission of NC such that

$(E 1+E 2)+2 E 1+(E 1$ orE2 $)+(E 1$ orE2 $)<(E 1+E 2)+$ $2 E 1+3 E 1+(E 1+E 2)+(E 1+E 2)$

Hence, we can conclude that vehicular emissions within a city can be reduced through partial and/or full collaboration between shippers meeting the demands of clients with goods vehicle delivery.

Table 7. Vehicular emissions

\begin{tabular}{|c|c|c|c|c|c|c|}
\hline $\begin{array}{c}\text { Types of } \\
\text { collaboration }\end{array}$ & $\begin{array}{l}\text { Possible } \\
\text { combinations } \\
\text { between shippers }\end{array}$ & $\begin{array}{l}\text { Route used } \\
\text { (with shortest path) }\end{array}$ & $\begin{array}{l}\text { Number } \\
\text { of } \\
\text { vehicles } \\
\text { used } \\
\end{array}$ & $\begin{array}{l}\text { Total } \\
\text { trip- } \\
\text { length }\end{array}$ & $\begin{array}{l}\text { Kinds of } \\
\text { vehicles } \\
\text { used(counts) }\end{array}$ & $\begin{array}{l}\text { Vehicular } \\
\text { emissions }\end{array}$ \\
\hline & & (S1-S6)-C2(15) & & & & \\
\hline FC & S1-S6 & (S1-S6)-C1-C3-C4(15) & 2 & 30 & $\mathrm{~T} 1, \mathrm{~T} 2$ & $E 1+E 2$ \\
\hline \multirow{4}{*}{ PC } & \multirow{2}{*}{ S2-S3 } & (S2-S3)-C6(10) & \multirow{2}{*}{2} & \multirow{2}{*}{25} & \multirow{2}{*}{$\mathrm{T} 4, \mathrm{~T} 5$} & \multirow{2}{*}{$2 \mathrm{E} 1$} \\
\hline & & (S2-S3)-C5-C7-C8(15) & & & & \\
\hline & S2-S4 & (S2-S4)-C7-C8(15) & 1 & 15 & T4 or T7or T8 & $\mathrm{E} 1$ or E2 \\
\hline & S2-S3-S4 & (S2-S3-S4)-C7-C8(10) & 1 & 10 & T4 or T5 or T7or T8 & $\mathrm{E} 1$ or E2 \\
\hline \multirow{5}{*}{ NC } & $\mathrm{S} 1$ & $\begin{array}{l}\text { S1-C2(15) } \\
\text { S1-C1-C3-C4(15) } \\
\text { S2-C6-C7(20) }\end{array}$ & 2 & 30 & $\mathrm{~T} 1, \mathrm{~T} 2$ & $\mathrm{E} 1+\mathrm{E} 2$ \\
\hline & S2 & S2-C5-C8(15) & 1 & 35 & T4 & $2 \mathrm{E} 1$ \\
\hline & S3 & $\begin{array}{l}\text { S3-C6(10) } \\
\text { S3-C7-C8(10) } \\
\text { S3-C10(25) }\end{array}$ & 1 & 45 & T5 & $3 \mathrm{E} 1$ \\
\hline & \multirow[t]{2}{*}{ S4 } & $\begin{array}{l}\text { S4-C7-C8(15) } \\
\text { S4-C9-C11(25) }\end{array}$ & 2 & 40 & $\mathrm{~T} 7, \mathrm{~T} 8$ & $E 1+E 2$ \\
\hline & & $\begin{array}{l}\text { S6-C1(10) } \\
\text { S6-C3-C4-C2(20) }\end{array}$ & 2 & 30 & $\mathrm{~T} 1, \mathrm{~T} 2$ & $E 1+E 2$ \\
\hline
\end{tabular}

\section{CONCLUSION}

The collaboration of CL stakeholders is vital for sustainable urban transportation operations. It can help potential partners reduce excess inventory, shorten lead times, increase sales and customer service levels. Furthermore, it may allow organizations to enhance flexibility and capabilities by fostering relationships that increase skills and knowledge, facilitate easier logistic operations, offer access to new technologies and reduce time that can be seen as important factors for effective and efficient supply chain management.

We have presented our CM model at the macrolevel to evaluate the social-cultural characteristics, economy and environment impacts of the activities of city dwellers. In addition, we have shown how the collaboration strategies of the stakeholders can be useful at the operational level of CL system. Our operational level model can help CL stakeholders, through partial and full collaboration, lessen vehicles emissions causing pollutions in the city. In future, we shall seek to improve on accuracy and efficiency as well as reduce the gap using software tools for very large number of test cases. We shall also find the usability of $\mathrm{SN}$ collaboration by the stakeholders for sustainable CL operations.

\section{ACKNOWLEDGMENT}

The authors would like to thank Dr. Anjali Awasthi, Ms. Zorana Popić, Mr. Mostapha Badakhshian, and the anonymous referees for their constructive critiques and suggestions.

\section{REFERENCES}

Awasthi, A. and Proth, J. 2006. A systems-based approach for city logistics decision making. Advances in Management Research 3(2), pp. 7-17.

Barratt, M.A. 2004. Understanding the meaning of collaboration in the supply chain. Supply Chain Management 9 (1), pp. 30-34.

Beamon, B.M. 2008. Sustainability and the future of supply chain management. Operations and Supply Chain Management 1(1), pp. 4-18.

Crainic, T.G., Errico, F., Rei, W., and Ricciardi, N. 2011. Modelling demand uncertainty in two-tiered city logistics planning. CIRRELT-2011-54. CIRRELT(Centre interuniversitaire de recherché sur les 
réseaux d'enterprise, la logistique et le transport), Quebec, Canada, September.

Crainic,T.G. and Sgalambro, A. 2009b. Service network design models for two-tiers city. CIRRELT-2009-60. CIRRELT(Centre interuniversitaire de recherché sur les réseaux d'enterprise, la logistique et le transport), Quebec, Canada, December. Accessed January 23, 2012.

https://www.cirrelt.ca/DocumentsTravail/CIRRELT2009-60.pdf.

Dantzig, G.B. and Ramser, J.H. 1959. The truck dispatching problem. Journal of Management Science 6 (1), pp. 8091.

Evrard Samuel, K. and Spalanzani, A. 2009. Developing collaborative competencies within supply chains. International Journal of Information Technology and Management 8 (2), pp. 146-160.

Gartner Group. 1999. Report Entitled: Collaborativecommerce: The new arena for business applications. Gartner, Inc. Stamford,Connectiut.

Gloria, Ma. and Talavera, V. 2014. Supply chain collaboration and trust in the Philippines. Operations and Supply Chain Management 7 (1), pp. 1-12.

Gonzalez-Feliu, J., and Morana, J. 2011. Collaborative transportation sharing: from theory to practice via a case study from France. In Technologies for Supporting Reasoning Communities and Collaborative Decision Making: Cooperative Approaches, edited by J. Yearwood and A. Stranieri, pp. 252-271. Information Science Reference, Hershey, PA.

Gonzalez-Feliu, J., Morana , J. , Grau, J-M. S, and Ma, T-Y. 2013. Design and scenario assessment for collaborative logistics and freight transport systems. International Journal of Transport Economies, pp. 207-240.

Gragnani, S.,Valenti, G., and Valentini, M.P. 2003. City logisitics in Italy: A national project. Edited by $\mathrm{E}$ Taniguchi and R.G Thompson. Proceedings of the 3rd International Conference on City Logistics. Madeira, Portugal, pp. 279-293.

Horvath, L. 2001. Collaboration: key to value creation in supply chain management. Supply Chain Management 6 (5), pp. 205-207.

Lambert, D.M., Cooper, M., Pagh, J. 1998. Supply chain management: implementation issues and research opportunities. The International Journal of Logistics Management 9 (2), pp. 1-19.

Marquez, L., Smith, N., Kilsby, D.,Taylor, M., and Zito, R. 2003. Assessing impacts of greenhouse gas abatement measures on urban freight. In Taniguchi, E. and Thompson, R.G(eds.). Proceedings of the $3 \mathrm{rd}$ International Conference on City Logistics. Madeira, Portugal, pp. 191-205.
Nemat, R. 2011. Taking a look at different types of ecommerce. World Applied Programming(WAP) 1 (2): 100-104. WAP journal. www.waprogramming.com.

Osborne, M.J., and Rubinstein, A. 1994. A course in game theory. Cambridge, MA: MIT Press.

Pervez, G. 2013. Stakeholder collaboration modeling for efficient supply chain management. Master thesis. http://spectrum.library.concordia.ca/978000/1/Pervez MASc_S2014.pdf.

Plant, R.T. 2000. eCommerce formulation of strategy. Upper Saddle River, NJ 07458: PrenticeHall, Inc.

Roy, J., Landry, S., and Beaulieu, M. 2006. "Collaborer dans la chaîne logistique : où en sommes-nous?" Gestion. Revue Internationale de Gestion, 31 (3), pp. 70-77.

Segalou, E., Ambrosini, C. and Routhier, J-L. 2003, June 2527. The environment assessment of urban goods movement. In Taniguchi, E. and Thompson, R.G.(eds.). Proceedings of the 3rd International Conference on City Logistics. Madeira, Portugal. 208-220.

Simatupang, T.M. and Sridharan, R. 2002. The collaborative supply chain. International Journal of Logistics Management 13 (1), pp. 15 - 30.

Simonot, P.-Y., Roure, J. 2007. "Logistique collaborative. Une question d'avenir." Economica.

Stathopoulos, A., Valeri, E., and Marcucii, E. 2012. Stakeholders reactions to urban freight policy innovation. Transport Geography (Elsevier publisher Ltd) 22, pp. 34-45.

Taniguchi, E., Thompson R. G., and Yamada, T. 2012. Emerging techniques for enhancing the practical application of city logistics models. The Seventh International Conference on City Logistics. Procedia Social and Behavioral Sciences. 39, pp. 3-18.

Taniguchi, E., Thompson, R.G. and Yamada, T. 1999. Modeling city logistics. In: City Logistics I. In Taniguch E. and Thompson R.G. (ed.),. Institute of Systems Science Research, Kyoto, 3-37.

Taniguchi, E., Thompson, R.G., Yamada, T. and Van Duin, R. 2001. City logistics: Network modelling and intelligent transport systems. Pergamon, Amsterdam.

Taylor, M. A. P. n.d. The city logistics paradigm for urban freight transport. Vers. INFRASTRUCTURE $18-1$. University of South Australia Transport Systems Centre.

http://www.griffith.edu.au/_data/assets/pdf_file/0010/ 81397/infrastructure-18-taylor.pdf. Accessed December 24, 2011

Udin, Z.M., Mohtar, S., and Othman, A. A. 2008. Collaborative supply chain management: The hybrid knowledge-based development approach of supplierscustomers perspective. Operations and Supply Chain Managment 1 (2), pp. 130-141.

Taiwo Adetiloye is pursuing his Ph.D. in Information and Systems Engineering at CIISE, Concordia University, Montréal, Canada. He holds a Master in Quality Systems Engineering(2012) also at CIISE, Concordia University, Montréal, Canada, and a B.Sc. Degree in Electronic and Electrical Engineering(2006) from the Obafemi Awolowo University, Ife, Nigeria. His research interests include IT/IS decision support systems, supply chain optimisation, urban freight transport and logistics, and quality management. He is a member of the Canadian Operations Research Society, and the IEEE Society for Intelligent Transportation Systems.

Gul Pervez has a Master Degree in Quality Systems Engineering (2014) at CIISE, Concordia University, Montréal, Canada. He received a B.Eng. in Systems Engineering (2008) from the University of Warwick, Coventry, United Kingdom. His research interests include game theory, collaboration models for supply chain analysis, sustainable city logistics, strategic purchasing, planning \& control systems and supply chain sustainability. 